\title{
National Survey of Medication Safety Practice: Drug Information at Primary Healthcare Centers/Community Pharmacies in Riyadh, Saudi Arabia
}

\author{
Yousef Ahmed Alomi, (iD The \\ Former General Manager of General \\ Administration of Pharmaceutical \\ Care, The Former Head, National Clini- \\ cal pharmacy and pharmacy practice, \\ The Former Head, Pharmacy R and \\ D Administration, Ministry of Health, \\ Riyadh, SAUDI ARABIA. \\ Manar Mohammed Alslim, Staff \\ pharmacist, Prince Sultan Military \\ Medical City, Riyadh, SAUDI ARABIA. \\ Rana Mohammed Alslim, Staff \\ pharmacist, Ministry of Health, \\ Riyadh, SAUDI ARABIA. \\ Khulud Abdulrahman Alamoudi, \\ Narcotic in-charge, Alhammadi hos- \\ pital Riyadh, SAUDI ARABIA. \\ Zainab Abdulmunem Almual- \\ lem, Saudi Food and Drug Authority \\ Riyadh, SAUDI ARABIA. \\ Adel Mehmas H. Alragas, Medi- \\ cal city-king Saud university, Riyadh, \\ SAUDI ARABIA.

\section{Correspondence: \\ Yousef Ahmed Alomi, \\ Bsc. Pharm, MSc. Clin Pharm, BCPS, BCNSP, DiBA The Past General Manager of General Administration of Pharmaceutical Care Head, National Clinical pharmacy and pharmacy practice Head, Pharmacy R \& D Administration Ministry of Health, P.O.BOX 100, Riyadh 11392, Riyadh, SAUDI ARABIA.}

Phone no: +966504417712

E-mail: yalomi@gmail.com

Received: 12-08-2018;

Accepted: 29-09-2018

Copyright: (c) the author(s),publisher and licensee Pharmacology, Toxicology and Biomedical Reports. This is an open-access article distributed under the terms of the Creative Commons Attribution NonCommercial License, which permits unrestricted non-commercial use, distribution, and reproduction in any medium, provided the original work is properly cited.

This is an open access article distributed under the terms of the Creative Commons Attribution-NonCommercial-ShareAlike 4.0 License

\begin{tabular}{|c|c|}
\hline \multicolumn{2}{|c|}{ Access this article online } \\
\hline
\end{tabular}

\begin{abstract}
Objective: To explore regarding drug information at Primary Healthcare Centers (PHCs) and Community Pharmacies (CPs) in Riyadh city, Kingdom of Saudi Arabia. Methods: This is a 4-month crosssectional survey conducted at PHCs and CPs in Riyadh city. In this study, the survey was adapted and modified from the Institution of Safe Medication Practice (ISMP) medication safety self-assessment for community/ambulatory pharmacy. It consists of a demographic section and 10 domains with 198 questions. The domains captured the following information: patient information; drug information; communication of drug orders and other drug information; drug labeling and packaging and nomenclature; use of medication delivery devices; environmental factors; staff competency and education; patient education; quality processes; and risk management domain. The survey was conducted at PHCs of Ministry of Health and at CPs located in Riyadh city. This study is focused on the second domain, that is, drug information at PHCs and CPs in Riyadh city. Results: The survey was distributed to 13 PHCs and $23 \mathrm{CPs}$. The average \pm Standard Deviation (SD) of all ISMP-self assessment items of medication safety practice at PHCs was $2.75 \pm 0.36(54.94 \%)(95 \%$ Confidence Interval $(\mathrm{Cl})=2.55-2.95 ; P<0.05$; range = 2.04-3.38). The average score of all ISMP-self assessment items of medication safety practice at CPS was $3.14 \pm 0.42(62.86 \%)(95 \% \mathrm{Cl}=2.90-4.38 ; P<0.05$; range $=2.40-3.88)$. The average score of drug information domain at $\mathrm{PHCs}$ was $2.04 \pm 0.34(40.8 \%)(95 \% \mathrm{Cl}=1.89-2.19 ; P<0.05$; range $=1.50-2.73)$, whereas that at the CPs was $2.35 \pm 0.5(47 \%)(95 \% \mathrm{Cl}=2.13-2.57 ; P<0.05$; range $=1.61-3.43)$. Conclusion: The PHCs and CPs need to improve the key aspects of drug information related to the safety documentation and reporting system for medications. We recommend that the PHCs and CPs in the Kingdom of Saudi Arabia (KSA) should regularly conduct awareness programs on medication safety. We also recommend conducting an annual follow-up assessment of all the critical elements of drug information related to the medication safety system at PHCs and CPs.
\end{abstract}

Key word: Medication, Safety, Drug Information, Primary Healthcare Centers, Community Pharmacies, Riyadh, Saudi Arabia.

\section{INTRODUCTION}

The services provided by the PHCs are expanding in the KSA. ${ }^{1,2}$ Several PHCs are spread across the KSA which provide services to the Saudi people. Based on the services provided, the PHCs are classified into several types. ${ }^{3}$ They have ambulatory care clinics for internal medicine, pediatrics, obstetrics, gynecology, dental clinics, laboratory and pharmacy services. The pharmacy keeps a list of medications that are dispensed as essential medications. This list is considered as the PHCs drug formulary and is updated regularly through MOH's corporate Pharmacy and Therapeutic Committee (PTC) and General Administration of Pharmaceutical Care at PHCs. That's occurred during the implementation of strategic plan of the General Administration of Pharmaceutical Care in 2012 and later. ${ }^{4}$ There are about 10-20 drug information centers founded at PHCs., ${ }^{5,6}$ These centers have pharmacists and pharmacy technicians as the persons-in-charge of the activities such as sourcing, staffing and so on. ${ }^{6}$ In addition, PHCs started the implementation of medication safety practices through the national medication safety program and through the Saudi Central Board of Accreditation for Healthcare Institutions
(CBAHI)" ${ }^{7,8}$ Previous studies have investigated the discrepancies in medication safety practices with an emphasis on drug information. ${ }^{9,10} \mathrm{CPs}$ in Saudi Arabia work either independently or work as chains. Each chain competes with the other with different patients care services. There are more than $7000 \mathrm{CPs}$ in the KSA that dispense prescribed medications, over-the-counter medications, medication delivery devices and cosmetics. ${ }^{11}$ All medications in the CPs should be registered in the SFDA and all drugs marketed in Saudi must be listed out in the drug formulary of the CP. Several aspects of medications safety have been implemented in CPs but with some discrepancies. ${ }^{12,13}$ The CP should consider the medication safety aspect of $\mathrm{MOH}$, SFDA and recently Saudi patient safety centers. ${ }^{7,8,14,15}$ ISMP provides critical tools of self-assessment of medications safety in order to prevent drugrelated problems and improve medication safety aspect in the PHCs and CPs. Some of the previous studies conducted in the hospital pharmacies in the United States have shown the safety of drugs used in self-assessment tools with marked improvement in score in most components. The 
overall ISMP medication safety self-assessment score changed from $56 \%$ to $71 \%$. The highest cumulative changes recorded for the drug information, patient education, patient information and pharmacological information were $57.4 \%, 41.7 \%, 41.2 \%, 39.5 \%$ and $28.3 \%$, respectively. ${ }^{16,17} \mathrm{~A}$ local study was conducted during the Hajj in Saudi hospitals to monitor medication safety practices. The researchers found that the information on all areas of patient care in hospitals was $61 \%$ and there were computerized drug information resources in the pharmacy of $43 \%$ of the hospitals surveyed. ${ }^{18}$ To the best of our knowledge, there are no investigations conducted in Saudi Arabia, Gulf and Middle Eastern countries regarding the self-assessment of medications safety practice in the PHCs and CPs. Therefore, in this study, we aimed to explore the medication safety practice with an emphasis on drug information at PHCs and CPs in Riyadh, KSA.

\section{METHODS}

This is a 4-month cross-sectional survey conducted on medication safety practice at PHCs and CPs in Riyadh, KSA. The survey was adapted and modified from ISMP medication safety self-assessment for community/ ambulatory pharmacy..$^{19}$ It consists of a demographic section and 10 domains with 198 questions. The 10 areas included patient information; drug information; communication of drug orders and other drug information; drug labeling, packaging and nomenclature; use of medication delivery devices; environmental factors; staff competency and education; patient education; quality processes; and risk management domain. The survey was conducted at pharmacies of the PHCs at MOH and CPs located in Riyadh city. The responses were obtained using a 5-point Likert response scale system. The scoring key identified as number (1) is equal to (A): No activity to implement, (2) is equal to (B): Considered, but not implemented, (3) is equal to (C): Partially implemented in some or all areas, (4) is equal to (D): Fully implemented in some areas and (5) is equal to (E): Fully implemented throughout. The survey was distributed to the directors of PHCs and CPs. The authors distributed the questionnaire and followed-up on a daily basis by physically visiting the pharmacies or by making a telephonic call. The questionnaire was prepared in an electronic format and was analyzed through Survey Monkey system and Microsoft Excel version 10. The authors suggested some solutions to improve the scores of the medication safety practices as per the ISMP self-assessment items. The suggestions were based on the strategic plan of the General Administration of Pharmaceutical Care and CBAHI standards in Saudi Arabia. ${ }^{4,8}$ The 10 domains were divided into several parts for the ease of analysis, discussion and solution. Part one consisted of patient information; part two consisted of drug information; part three consisted of medication preparation and dispensing (Communication of drug orders and other drug information and drug labeling, packaging and nomenclature); part four consisted of medication administration (Drug standardization, storage and distribution and medication delivery devices acquisition, use and monitoring); part five consisted of environmental factors, workflow and staffing and staff competency; and part six consisted of patient education, quality processes and risk management. In this study, our emphasis is on part one of the medication safety selfassessment items.

\section{RESULTS}

The survey was distributed to 13 PHCs and 23 CPs. Majority of the PHCs was Types M1 and M3 (4 (30.8\%) and 3 (23.1\%) respectively). However, most of the CPs were large $(8(33.3 \%))$ and medium type $(8(33.3 \%))$. The majority of PHCs and CPs had Saudi commission of health specialties accreditation (7 (70\%) and 20 (87\%), respectively). Most of the PHCs dispensed more than 100 prescription medications on a daily basis (7 (53.9\%)), whereas most of the CPs dispensed less than 20 (11 (45.8\%)).
Most of the responders in PHCs were females (9 (69.2\%)) (4 (30.8\%) were male responders), whereas all the responders in CPs were males (25 $(100 \%))$. The majority of responders in PHCs was Saudi individuals (12 $(92.3 \%)$ ), whereas those in CPs were non-Saudi individuals $(25(100 \%))$. Most of the responders $(9(69.2 \%))$ in PHCs were in the age group of 30 44 years, whereas those in the CPs were in the age group of 18-29 years (15 (62.5\%)). Most of the responders in PHCs had obtained a diploma, a Bachelor of Science (B.Sc.,) in Pharmacy and a Master of Science in Clinical Pharmacy (2 (22.2\%), 3 (33.3\%) and 2 (22.2\%), respectively). Most of the responders in CPs had obtained B.Sc., in Pharmacy $(22$ (88\%)). The majority of the pharmacy staff did not have accreditation from the board of pharmaceutical specialties; $8(88.9 \%)$ and 21 (91.3\%) responders were working in the PHCs and CPs, respectively. The average \pm Standard Deviation (SD) score of all ISMP-self-assessment of medication safety at PHCs was $2.75 \pm 0.36$ (54.94\%) $(95 \%$ confidence interval $(95 \% \mathrm{CI})=$ $2.55-2.95 ; P<0.05$; range $=2.04-3.38)$. The average score of all ISMP-self assessment of medication safety at $\mathrm{CP}$ was $3.14 \pm 0.42(62.86 \%)(95 \% \mathrm{CI}=$ $2.90-4.38 ; P<0.05 ;$ range $=2.40-3.88)$. The average of drug information domain at PHCs were $2.04 \pm 0.34$ (40.8\%) (95\% CI $=1.89-2.19 ; P<0.05$; range $=1.50-2.73)$. The average of drug information domain at $\mathrm{CP}$ were $2.35 \pm 0.5(47 \%)(95 \% \mathrm{CI}=2.13-2.57 ; P<0.05$; range $=1.61-3.43)$. The highest score of drug information key element at essential drug information score was the computer system automatically performs adult dose range checks and warns practitioners 2.58 (51.6\%) at PHCs, whereas dispensing areas are well stocked with easily accessible, updated drug reference texts and all outdated texts were removed from use $3.43(68.6 \%)$ CPs. The highest score in the controlled drug formulary system core was the new drugs with heightened error potential are identified, safety enhancement at PHCs 2.73 (54.6\%), while the statement at least quarterly, current drug inventory on shelves is reviewed and reduced as appropriate to minimize duplication of generically equivalent products was at CPs 3.04 (60.8\%) (Table 3). The lowest score of drug information key element at essential drug information core was A designated pharmacist or corporate level staff routinely reviews, for quality improvement purposes, reports of computer warnings that are overridden by pharmacists $1.50(30 \%)$ at PHCs, while the computer system warns practitioners about clinically significant drug interactions 1.61 (32.2\%) CP. The lowest score in the A controlled drug formulary system core was After a drug is on the market for several months, a staff or corporate level pharmacist is assigned responsibility to determine the medication errors or adverse reactions have been reported internally or externally at PHCs $2.00(40 \%)$ and $2.22(44.4 \%)$ for CP (Table 4$)$.

\section{DISCUSSION}

The drug information centers have been founded since more 30 years in the $\mathrm{KSA}^{6}$ and the drug information services were established at $\mathrm{MOH}$ institutions in the 1980s. Most of the drug information services are provided in the hospital and in the PHCs. ${ }^{5}$ These centers are not well established at private hospitals and in CPs. The private hospitals do not have drug information resources available to healthcare providers and the inpatient pharmacist covers the job. The average scores in this study were found to be low in comparison to the previously published international or local studies conducted at hospitals. ${ }^{15-17}$ As a result, the hospital drug information services well established while PHCs or CPs not so. Furthermore, drug information resources are few and old editions. The missing of complete services of drug information may implicate of absent of the right information and progress to drug-related errors. The highest key elements statement at both PHCs was the following up and documentation of medications safety problems of newly marketed medications not well established. That's main the reporting system errors of both places maybe low and connection to SFDA not well established. Education and 


\section{Table 1: Demographic Hospital Information.}

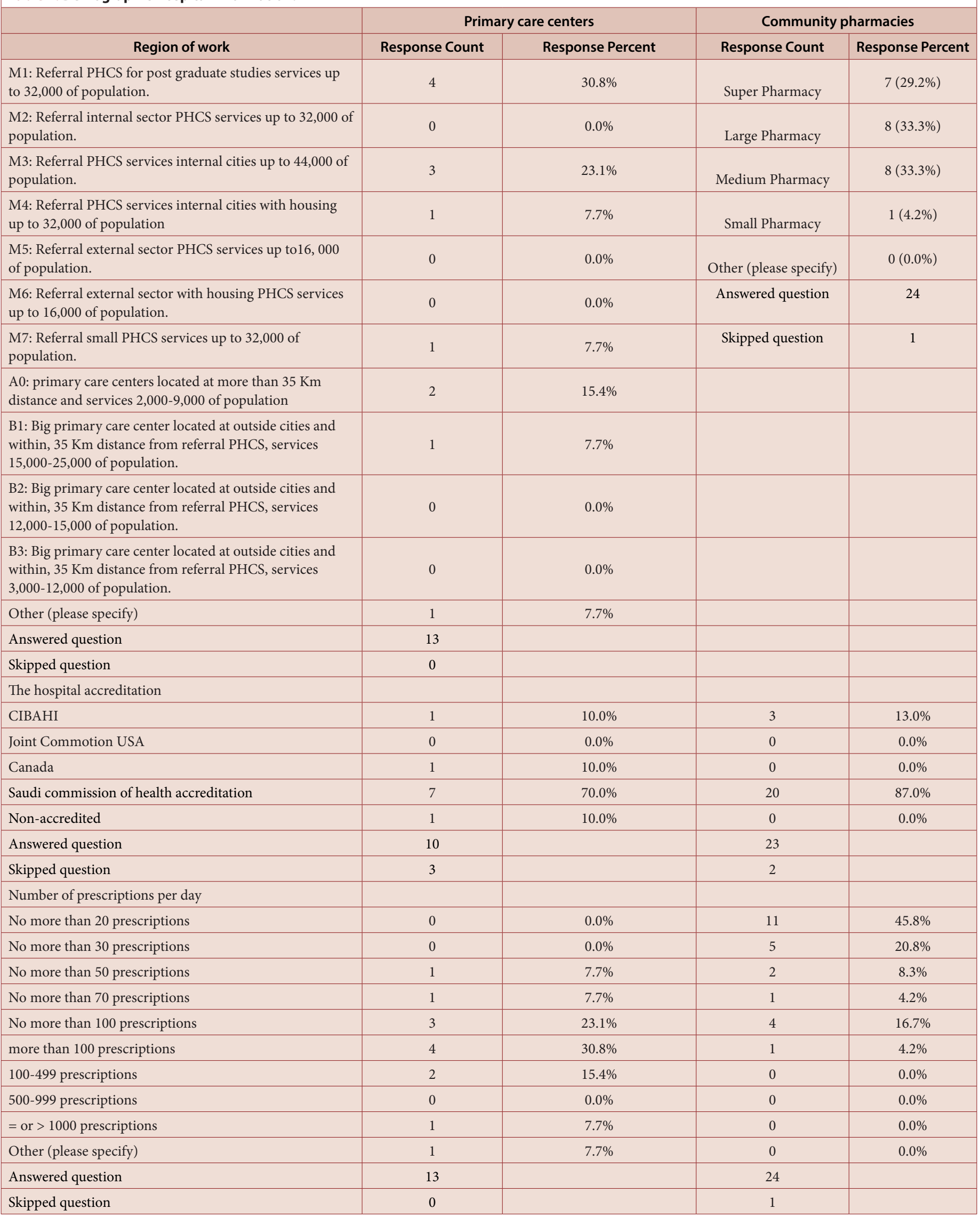




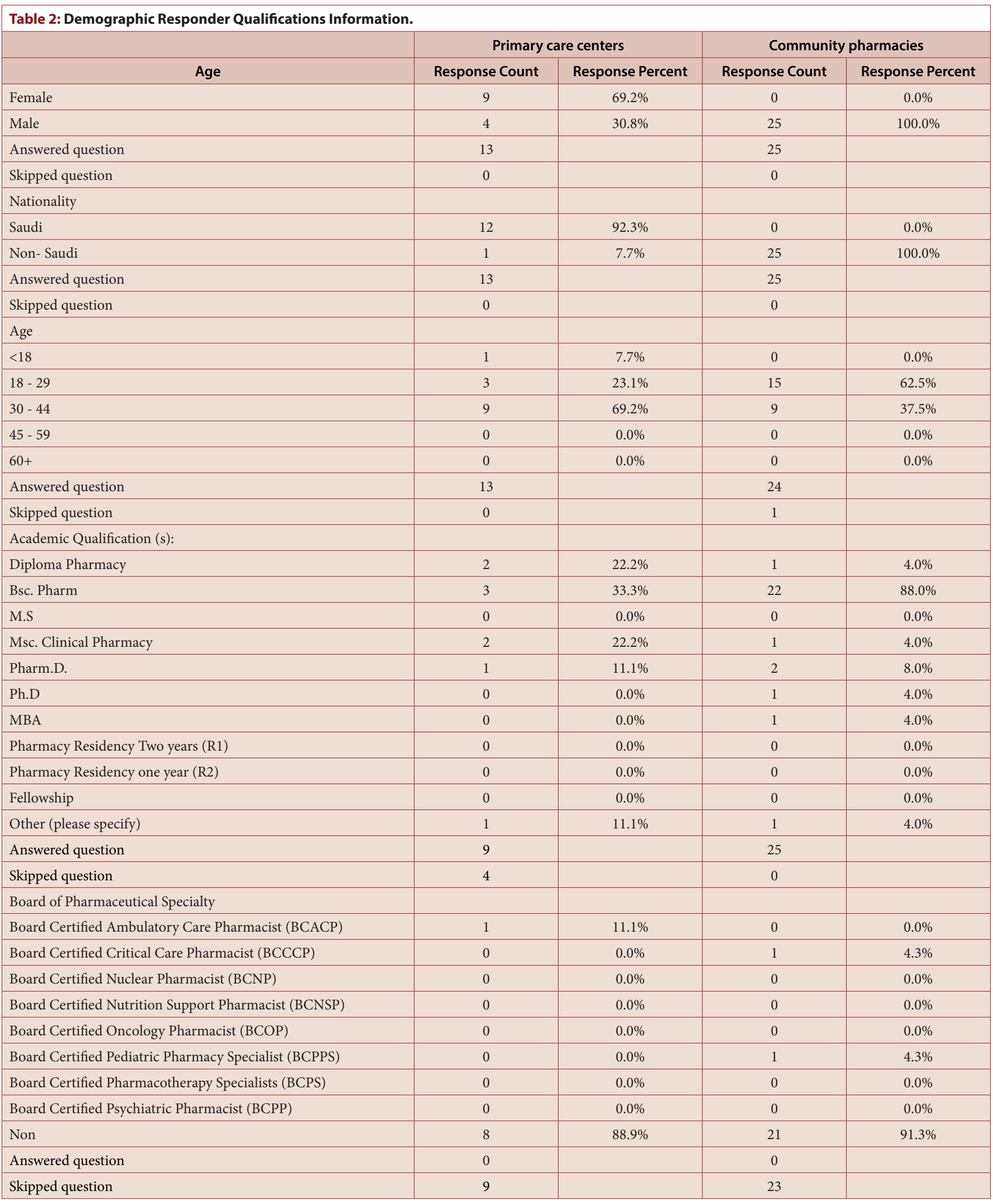




\begin{tabular}{|c|c|c|c|c|c|c|c|c|c|}
\hline \multicolumn{10}{|c|}{ Drug Information } \\
\hline \multirow[t]{2}{*}{ No } & \multirow[t]{2}{*}{ Key elements } & \multirow{2}{*}{\begin{tabular}{|l|} 
E \\
1
\end{tabular}} & \multirow[t]{2}{*}{ D } & \multirow{2}{*}{$\begin{array}{l}\text { C } \\
3\end{array}$} & \multirow{2}{*}{$\begin{array}{l}\text { B } \\
4\end{array}$} & \multirow[t]{2}{*}{ A } & \multirow{2}{*}{ 正 } & \multirow{2}{*}{ 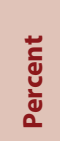 } & \multirow{2}{*}{ 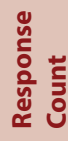 } \\
\hline & & & & & & & & & \\
\hline & Primary Care Center Pharmacy, Core \# 2 Essential drug information PHCS & & & & & & & & \\
\hline 20 & $\begin{array}{l}\text { E) The computer system automatically performs adult dose range checks and warns } \\
\text { practitioners about overdoses and under doses for targeted high-alert or narrow } \\
\text { therapeutic index medications and for most other drugs. }\end{array}$ & 6 & 1 & 1 & 0 & 4 & 2.58 & 51.6 & 12 \\
\hline \multirow[t]{2}{*}{16} & $\begin{array}{l}\text { A) Dispensing areas are well stocked with easily accessible, updated drug reference } \\
\text { texts and all outdated texts are removed from use. (Texts are outdated after one year } \\
\text { of publication or whenever the next edition is available.) }\end{array}$ & 5 & 2 & 2 & 0 & 3 & 2.50 & 50 & 12 \\
\hline & Community Pharmacy. Core \# 2 Essential drug information & & & & & & & & \\
\hline 16 & $\begin{array}{l}\text { A) Dispensing areas are well stocked with easily accessible, updated drug reference } \\
\text { texts and all outdated texts are removed from use. (Texts are outdated after one year } \\
\text { of publication or whenever the next edition is available.) }\end{array}$ & 3 & 3 & 5 & 5 & 7 & 3.43 & 68.6 & 23 \\
\hline \multirow[t]{2}{*}{17} & $\begin{array}{l}\text { B) Pharmacy computers that are used for order entry allow seamless, easy access } \\
\text { to the Internet to search for information about disease processes, drug dosing and } \\
\text { availability, unusual uses of drugs and other drug-related information. }\end{array}$ & 6 & 1 & 5 & 5 & 6 & 3.17 & 63.4 & 23 \\
\hline & Primary Care Center Pharmacy Core \# 3 A controlled drug formulary system & & & & & & & & \\
\hline 37 & $\begin{array}{l}\text { V) When new drugs with heightened error potential are identified, safety } \\
\text { enhancement(s) (e.g., check systems, alert labels, reminders, limitations on use, } \\
\text { sequestered storage and location, etc.) are established before initial use. }\end{array}$ & 4 & 2 & 1 & 1 & 3 & 2.73 & 54.6 & 11 \\
\hline \multirow[t]{2}{*}{35} & $\begin{array}{l}\text { T) The variety of manufacturers from whom generic drugs are purchased is } \\
\text { minimized to the fullest extent possible. }\end{array}$ & 2 & 4 & 4 & 1 & 1 & 2.58 & 51.6 & 12 \\
\hline & Community Pharmacy Core \# 3 A controlled drug formulary system & & & & & & & & \\
\hline 34 & $\begin{array}{l}\text { S) At least quarterly, current drug inventory on shelves is reviewed and reduced as } \\
\text { appropriate to minimize duplication of generically equivalent products. }\end{array}$ & 3 & 8 & 2 & 5 & 5 & 3.04 & 60.8 & 23 \\
\hline 36 & $\begin{array}{l}\text { U) When a new item is added to the pharmacy inventory, the potential for error with } \\
\text { that drug (e.g., sound-alike names, look-alike packaging, complex instructions for } \\
\text { patients, confusing dosing parameters, rigorous clinical monitoring requirements, } \\
\text { etc.) is evaluated. Published medication error features in journals or newsletters are } \\
\text { used to supplement the evaluation process. }\end{array}$ & 7 & 4 & 4 & 1 & 6 & 2.77 & 55.4 & 23 \\
\hline
\end{tabular}

Table 4: The Lowest Scores Items of Core Domain Essential Drug Information (Primary Care Center Pharmacy/Community Pharmacy).

Drug Information

\begin{tabular}{|c|c|c|c|c|c|c|c|c|c|}
\hline \multicolumn{10}{|c|}{ Drug Information } \\
\hline No & Key elements & $\begin{array}{l}E \\
1\end{array}$ & D & C & B & A & 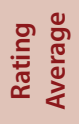 & 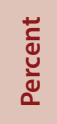 & 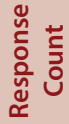 \\
\hline \multicolumn{10}{|c|}{ Primary Care Center Pharmacy, Core \# 2 Essential drug information PHCS } \\
\hline 31 & $\begin{array}{l}\text { P) The pharmacy computer system warns staff when a new drug has been entered for which there } \\
\text { is no screening information in the interactive database. }\end{array}$ & 8 & 2 & 1 & 1 & 0 & 1.58 & 31.6 & 12 \\
\hline \multirow[t]{2}{*}{32} & $\begin{array}{l}\text { Q) A designated pharmacist or corporate level staff routinely reviews, for quality improvement } \\
\text { purposes, reports of computer warnings that are overridden by pharmacists. }\end{array}$ & 8 & 2 & 2 & 0 & 0 & 1.50 & 30 & 12 \\
\hline & Community Pharmacy. Core \# 2 Essential drug information & & & & & & & & \\
\hline 23 & $\begin{array}{l}\text { H) The computer system automatically screens and detects drugs to which patients are allergic } \\
\text { (including cross allergies) and provides a clear warning to staff during order entry. }\end{array}$ & 13 & 5 & 3 & 2 & 0 & 1.74 & 34.8 & 23 \\
\hline
\end{tabular}




\begin{tabular}{|c|c|c|c|c|c|c|c|c|c|}
\hline 22 & G) The computer system warns practitioners about clinically significant drug interactions. & 15 & 4 & 2 & 2 & 0 & 1.61 & 32.2 & 23 \\
\hline & Primary Care Center Pharmacy Core \# 3 A controlled drug formulary system & & & & & & & & \\
\hline 34 & $\begin{array}{l}\text { S) At least quarterly, current drug inventory on shelves is reviewed and reduced as appropriate to } \\
\text { minimize duplication of generically equivalent products. }\end{array}$ & 5 & 1 & 5 & 0 & 1 & 2.25 & 45 & 12 \\
\hline 38 & $\begin{array}{l}\text { W) After a drug is on the market for several months, a staff or corporate level pharmacist is assigned } \\
\text { responsibility to determine if medication errors or adverse reactions have been reported internally } \\
\text { or externally since product launch and safety enhancements are established in the pharmacy as } \\
\text { necessary. }\end{array}$ & 6 & 1 & 4 & 1 & 0 & 2.00 & 40 & 12 \\
\hline & Community Pharmacy Core \# 3 A controlled drug formulary system & & & & & & & & \\
\hline 37 & $\begin{array}{l}\text { V) When new drugs with heightened error potential are identified, safety enhancement(s) (e.g., } \\
\text { check systems, alert labels, reminders, limitations on use, sequestered storage and location, etc.) } \\
\text { are established before initial use. }\end{array}$ & 9 & 5 & 3 & 1 & 5 & 2.48 & 49.6 & 23 \\
\hline 38 & $\begin{array}{l}\text { W) After a drug is on the market for several months, a staff or corporate level pharmacist is assigned } \\
\text { responsibility to determine if medication errors or adverse reactions have been reported internally } \\
\text { or externally since product launch and safety enhancements are established in the pharmacy as } \\
\text { necessary. }\end{array}$ & 8 & 8 & 4 & 0 & 3 & 2.22 & 44.4 & 23 \\
\hline
\end{tabular}

awareness program are required to improve those safety elements. The CPs had a good system for inventory management and they removed all old drug or information related issues. They had good system inventory to prevent duplication of generic medications getting errors. Some PHCs had alerting system during dispensing medications which made it. The highest safety statement at PHCs. Despite the seldom finding of computerized physician order entry at PHCs. Where the CPs had drug inventory management system and the computer did a good job. The PHCs had accepted monitoring of new medications added to the medications list or formulary. It required from local standards and made a high score of crucial safety elements. The PHCs and CPs need to improve the key aspects of drug information related medications safety documentation and reporting system. The awareness program of medications safety is highly recommended at PHCs and CPs in the KSA. The study is better to relate annually to follow up the critical elements of drug information related to the medications safety system at PHCs and CPs.

\section{CONCLUSION}

This study was first conducted in Saudi Arabia, the Gulf and the Middle Eastern countries. The medication safety with the emphasis of drug information in the practice of PHCs and CPs required for improvement. An electronic prescribing system with drug information alerting medication safety is highly recommended in practice PHCs and CPs in the KSA.

\section{ACKNOWLEDGMENT}

I want to thank all directors of all primary healthcare centers and community pharmacies for their cooperation and completion of the survey.

\section{CONFLICTS OF INTEREST}

The authors declare no conflict of interest

\section{ABBREVIATIONS}

PHCs: Primary healthcare centers; CPs: Community pharmacies; CBAHI: Saudi Central Board of Accreditation for Healthcare Institutions; ISMP: Institution of Safe Medication Practice; MOH: Ministry of Health; SFDA: Saudi Food and Drug Authority; KSA: Kingdom of Saudi Arabia; USA: United States of America.

\section{ORCID ID}

Yousef Ahmed Alomi (D) https://orcid.org/0000-003-1381-628X.

\section{REFERENCES}

1. Alomi YA, Alghamdi SJ, Alattyh RA. Primary Care Center Pharmacist's Workforce in Eleven-Year 2006-2016 at Ministry of Health in Saudi Arabia. J Pharm Pract Community Med. 2018;4(1s):S126-31.

2. Alomi YA. New Pharmacy Model for Vision 2030 in Saudi Arabia. J Pharm Pract Community Med. 2017;3(3)

3. Alomi YA. Primary Care Center Pharmacy Manpower New Guidelines in Saudi Arabia. J Pharmacol Clin Res. 2016;1(1).

4. Alomi YA, Alghamdi SJ, Alattyh RA. Strategic Plan of General Administration of Pharmaceutical Care at Ministry of Health in Saudi Arabia 2012 - 2022. J Pharm Pharm Scien. 2015;1(13):1-8.

5. Ahmed AY. National Primary Care Pharmacist Competency System at $\mathrm{MOH}$ in Saudi Arabia. J Pharma Pharm Sci. 2016;1(4):1-5

6. YA A. National Drug Information Center Program at Ministry of Health in Saudi Arabia. Adv Pharmacoepidemiol Drug Saf. 2016;5(1):1-2.

7. Alomi YA. National Medication Safety Program at Ministry of Health in Saudi Arabia. J Pharmacovigil. 2015;3(5):e145.

8. Medication management system. Saudi Center Board for Accreditation for Healthcare Institutions (CBAHI). 2016.

9. Khoja T, NeyazY, Qureshi NA, Magzoub MA, Haycox A, Walley T. Medication errors in primary care in Riyadh city, Saudi Arabia. EMHJ. 2011;17(2):156-9.

10. Alsulami Z, Conroy S, Choonara I. Medication errors in the Middle East countries: A systematic review of the literature. European Journal of Clinical Pharmacology. 2013;69(4):995-1008.

11. Alageel S, Abanmy NO. Counselling practices in community pharmacies in Riyadh, Saudi Arabia: A cross-sectional study. BMC Health Serv Res. 2015;15(1):19.

12. Al-Arifi MN. Community pharmacists' attitudes toward dispensing errors at community pharmacy setting in Central Saudi Arabia. Saudi Pharm J. 2014;22(3):195-202.

13. Al-Hazmi NN, II N. A Study of Community Pharmacists? Awareness and Contributions to Adverse Drug Reactions (ADRs) Reporting Systems in the Makkah, Kingdom of Saudi Arabia (KSA). J Clin Trials. 2013;3(1):1-5.

14. Smetzer JL, Vaida AJ, Cohen MR, Tranum D, Pittman MA, Armstrong CW. Findings from the ISMP Medication Safety Self-Assessment for hospitals. Jt Comm J Qual Saf. 2003;29(11):586-97.

15. Vaida AJ, Smetzer JL, Lamis RL, Cohen MR, Kenward K. Assessing the state of safe medication practices using the ISMP medication safety self assessment $\circledast$ for hospitals: 2000 and 2011. Jt Comm J Qual Patient Saf. 2014;40(2):51-67.

16. Ahmed AY, Adnan YKN, Jamil BM, Abdulraheem BY, Mohammed AJH. National Survey of Hospital Medication Safety Practice during Mass Gathering (Hajj2016) in Makkah, Saudi Arabia: Drug Information. J Pharm Pract Community Med. 2017;3(4s):S8-14.

17. Institute for Safe Medication Practices. ISMP Medication Safety SelfAssess $\neg$ ment for Hospitals. 2011 